\title{
Monoclonal antibody binding to congophilic elements in human Alzheimer brain
}

\author{
S M MACDONALD, * MARGARET M ESIRI $\dagger$ \\ From the Departments of *Haematology and $\dagger$ Neuropathology, John Radcliffe Infirmary, Oxford
}

SUMMARY Immunohistochemical studies, using a monoclonal antibody, SMP, raised in a mouse against aged human peripheral blood white cells, are described. This antibody reacts with dendritic reticulum cells in lymph node and tonsil, and, in Alzheimer brain, with argyrophilic plaques, neurofibrillary tangles, and cerebral vascular amyloid.

Alzheimer's disease, the commonest cause of senile and presenile dementia, is characterised pathologically by the presence of large numbers of argyrophilic plaques and neurofibrillary tangles in the hippocampus and neocortex of the brain. ${ }^{1}$ The stimulus to the development of these abnormal structures is unknown. One view proposes that argyrophilic plaque development may be attributable to disordered immune function. ${ }^{2}$ While evidence put forward so far in support of this view is inconclusive, the possibility that changes in the expression of cellular antigens with advancing age may have a role in the development of age related diseases such as Alzheimer's disease, is a reasonable one. An attempt was therefore made to raise monoclonal antibodies that react specifically with cellular components from aged humans, and we report here one result of such an attempt; the generation of a monoclonal antibody that reacts intensely with the congophilic elements in human Alzheimer brain, identified as SMP.

\section{Methods}

GENERATION OF MONOCLONAL ANTIBODY SMP The antibody was produced by cells formed by fusion of mouse myeloma cells with spleen lymphocytes taken from a mouse that had been immunised with pooled peripheral blood mononuclear cells from several aged human donors (aged 71-82 years). One mouse (BALB/C) was first hyperimmunised with $5 \times$ $10^{7}$ tonsil cells from a young donor (aged 24 years), injected subcutaneously to render the mouse tolerant to non-aged peripheral blood mononuclear cells. Two months later the mouse was injected subcutaneously with $2 \times 10^{6}$ peripheral blood mononuclear cells from three aged donors, followed two weeks later by

Accepted for publication 13 March 1986 an intravenous injection of $3 \times 10^{6}$ peripheral blood mononuclear cells from a different group of six aged donors, and a simultaneous intraperitoneal injection of $1 \times 10^{6}$ peripheral blood mononuclear cells from the same aged donors. Cells from several donors were used to increase the probability of raising antibodies to an antigen common to all aged cells. The spleen cells from this mouse were fused with a myeloma mouse line (P3/NS1/I-Ag 4-1), and colonies were cloned out by limiting dilution. Supernatants were assessed for antibody activity by screening on aged peripheral blood mononuclear cells and on Alzheimer brain tissue.

\section{IMMUNOHISTOLOGY}

Tissue samples for detection of monoclonal antibody binding from cerebral cortex of cases of Alzheimer's disease and elderly and young control necropsy brains were cut into 5-7 mm cubes, covered in mounting medium (Tissue Tek II, Lamb, United Kingdom) and frozen in isopentane cooled in acetone and dry ice. Cortical samples from four cases of Alzheimer's disease were examined. These showed numerous argyrophilic plaques and neurofibrillary tangles. Cryostat sections $(5 \mu \mathrm{m})$ were cut on a freezing microtome and air dried or fixed in acetone at $-20^{\circ} \mathrm{C}$. Sections were treated with SMP monoclonal antibody neat for 30 minutes at room temperature and then washed three times in minimal essential medium. Slides were then overlaid with sheep antimouse antiserum diluted $1 / 20$ for 30 minutes, and washed and layered with a complex of monoclonal antibody with alkaline phosphatase and alkaline phosphatase $(8 \mathrm{mg} / \mathrm{ml}$, Sigma) for a further 30 minutes. Sections were washed again and substrate added $(2 \mathrm{mg}$ naphthol As-Mx phosphate (Sigma) dissolved in $0.2 \mathrm{ml}$ of dimethyl formamide and made up to $10 \mathrm{ml}$ with $0.1 \mathrm{M}$ Tris buffer, $\mathrm{pH} 8 \cdot 2$, to which was added $1 \mathrm{mg}$ of 
levamisole (to block endogenous enzyme activity) and $1 \mathrm{mg}$ of fast red TR salt). The substrate was filtered before use and applied directly to the slide. Positive reaction gave a red precipitate.

In some experiments application of neat SMP monoclonal antibody for 30 minutes was followed by peroxidase conjugated antiserum to mouse immunoglobulin and the diaminobenzidine reaction, resulting in a brown reaction product. Alternatively, in double labelling experiments binding sites of SMP were detected using fluorescein labelled antiserum to mouse immunoglobulin following treatment with neat SMP monoclonal antibody for 30 minutes and reaction with monoclonal antibody RT97 neurofilament antibody detected by layering on neat RT97 monoclonal antibody for 30 minutes followed by three washes with minimal essential medium and application of a peroxidase labelled antiserum to mouse immunoglobulin. This sequential treatment of the section with monoclonal antibodies SMP and RT97 did not result in non-specific binding, nor did it prevent binding of the second monoclonal antibody to the section. For silver staining sections were fixed in $10 \%$ neutral formalin for 30 minutes before carrying out the standard von Braunmühl technique. Amyloid was detected with Congo red. The affinity of SMP monoclonal antibody for peripheral blood mononuclear cells was assessed using blood' smears fixed in acetone and stained with SMP monoclonal antibody followed by fluorescein conjugated antimouse immunoglobulin. Binding of SMP to peripheral blood mononuclear cells was also studied using a fluorescence activated cell sorter (FACS). Samples of
Table Quantitation of SMP positive cells in peripheral blood mononuclear cells from young, aged, and Alzheimer groups

\begin{tabular}{llll}
\hline & \multicolumn{3}{l}{ Mean $(S E)$ percentage of cells labelled } \\
\cline { 2 - 4 } & Young & Aged & Alzheimer \\
\hline SMP positive & $1.3(0.3)$ & $2.3(0.6)$ & $0.8(0 \cdot 18)$
\end{tabular}

Antibody binding detected with fluorescence antisera to mouse IgG using a FACS.

normal body tissues were screened for reactivity with SMP monoclonal antibody in frozen sections treated in the same way as the sections of cerebral cortex described above.

\section{Results}

Preliminary analysis of antibody containing supernatants showed that although no antibodies were produced which were specific for all aged peripheral blood mononuclear cells, a monoclonal antibody was produced (SMP) that reacted with about $2 \%$ of aged and young peripheral blood mononuclear cells (table) using FACS analysis and with an antigen present in sections of Alzheimer brain. Using specific antisera (Birmingham University) in an Ouchterlony test, SMP was found to be of IgG2a class. We were not able to confirm staining of peripheral blood mononuclear cells in blood smears.

Treatment of normal brain with SMP gave negative results apart from slight staining of collagen containing vascular elements. The results of treatment of

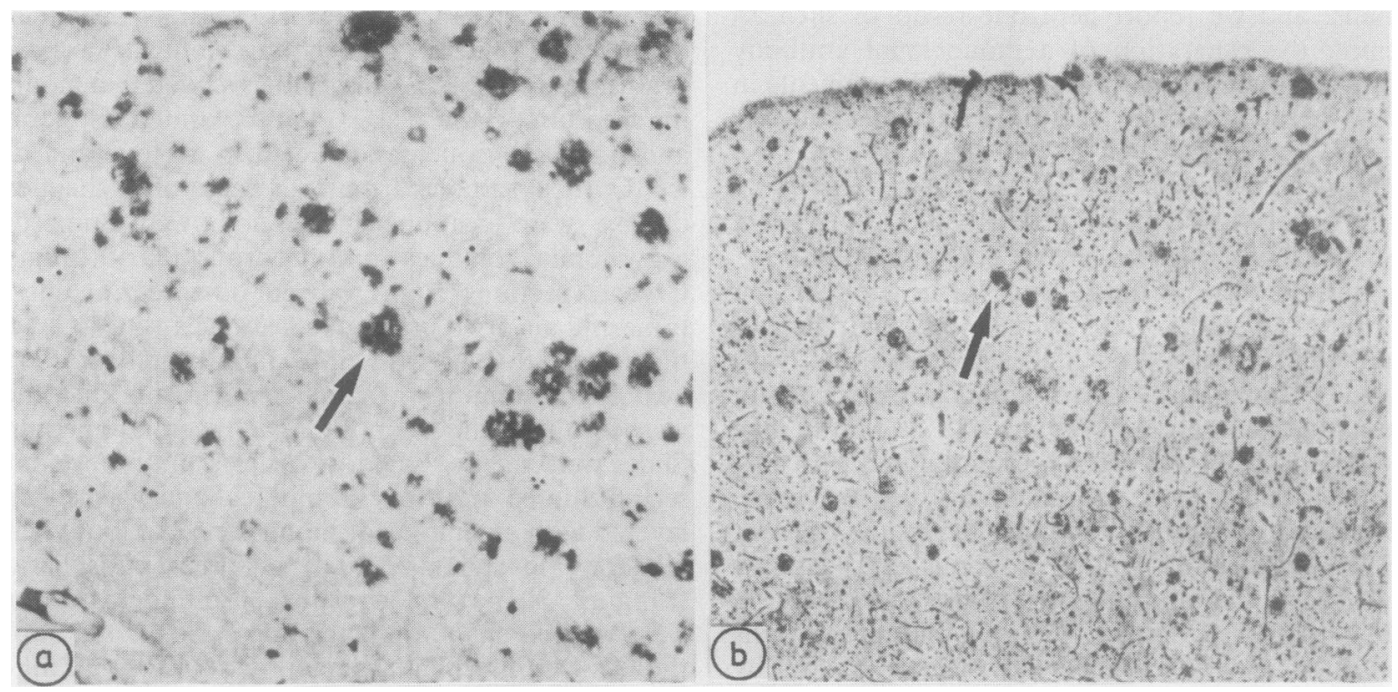

Fig 1 Appearance of Alzheimer cortex (cryostat sections) after treatment with SMP monoclonal antibody (a) and after staining with von Braunmühl silver stain (b). Examples of plaques are indicated by arrows. $a \times 130, b \times 90$. 


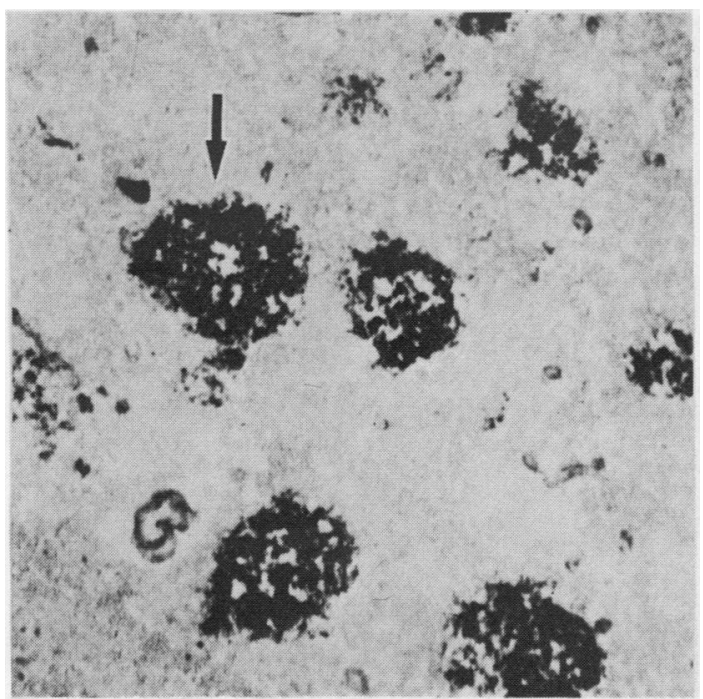

Fig 2 Higher power view of cryostat section of Alzheimer cortex after reaction with SMP monoclonal antibody. Example of plaque indicated by arrow. $\times 500$.

Alzheimer brain sections with SMP were compared with the staining patterns obtained using silver staining (von Braunmühl) and staining for amyloid (Congo red) and neurofilaments (monoclonal antibody $\mathrm{RT} 97^{3}$ ). The staining pattern of SMP reactivity was very similar at low and high power magnification to that obtained with silver staining of plaques (figs 1 and 2). The number of senile plaques identified with
SMP and silver, counted at low power in $1.5 \mathrm{~mm}$ diameter circles, was very similar (35 with SMP, 37 with silver). SMP binding in plaques showed some overlap with amyloid as shown by Congo red staining but was more extensive. Leptomeningeal and cortical vessels in which amyloid was deposited in Alzheimer brain, however, showed coextensive binding of SMP (fig 3). The neurofilament specific monoclonal antibody RT97 did not stain all plaques demonstrable with silver and SMP, but where plaques could be identified with RT97 there was also staining with SMP (fig 4). SMP bound more extensively than RT97 to those plaques that were doubly reactive. Neurofibrillary tangles, which are strongly reactive with $\mathrm{RT} 97^{3}$, were also moderately reactive with SMP (fig 5).

We investigated the affinity of SMP for other body constituents in an attempt to further characterise the antigen. Sections of pituitary, pineal, and extracranial viscera from normal subjects were screened and did not show binding of SMP, apart from very minimal staining of connective tissue. Stronger binding of SMP was seen in the germinal centres of lymphoid follicles. In acetone fixed smears made from fresh tonsil the pattern of SMP binding resembled that of certain other monoclonal antibodies believed to react with dendritic reticulum cells: E11 (M Slusarenko, P Beverley) and dendritic reticular cell antibody (D Mason) (fig 6). These monoclonal antibodies, however, did not bind to Alzheimer brain. The possibility that SMP was identifying immunoglobulin light chains in senile plaques ${ }^{3-5}$ was discounted as we

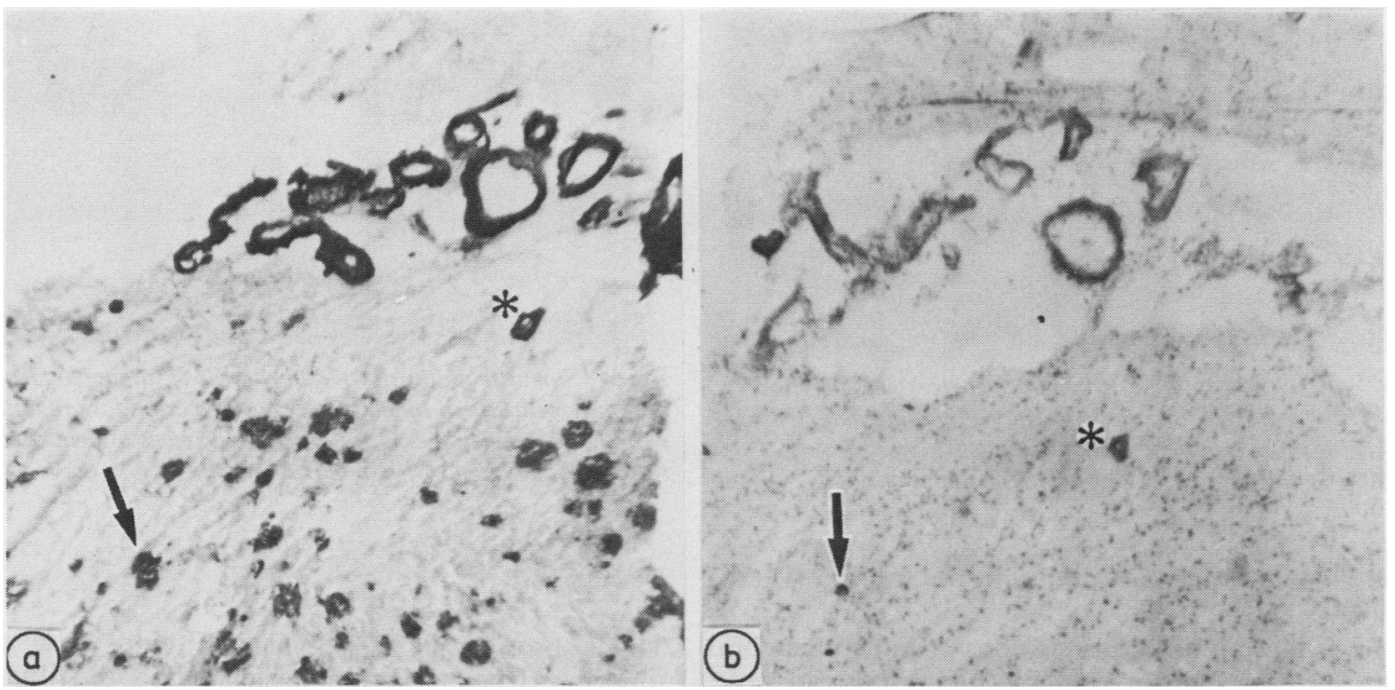

Fig 3 (a) Adjacent sections of Alzheimer cortex showing leptomeningeal arteries and cortical arteriole (*) and plaques (examples arrowed) after reaction with SMP monoclonal antibody $(a)$ and Congo red $(b)$. SMP binding and amyloid deposits coincide in vessels, but SMP binding is more extensive in plaques. $\times 120$. 

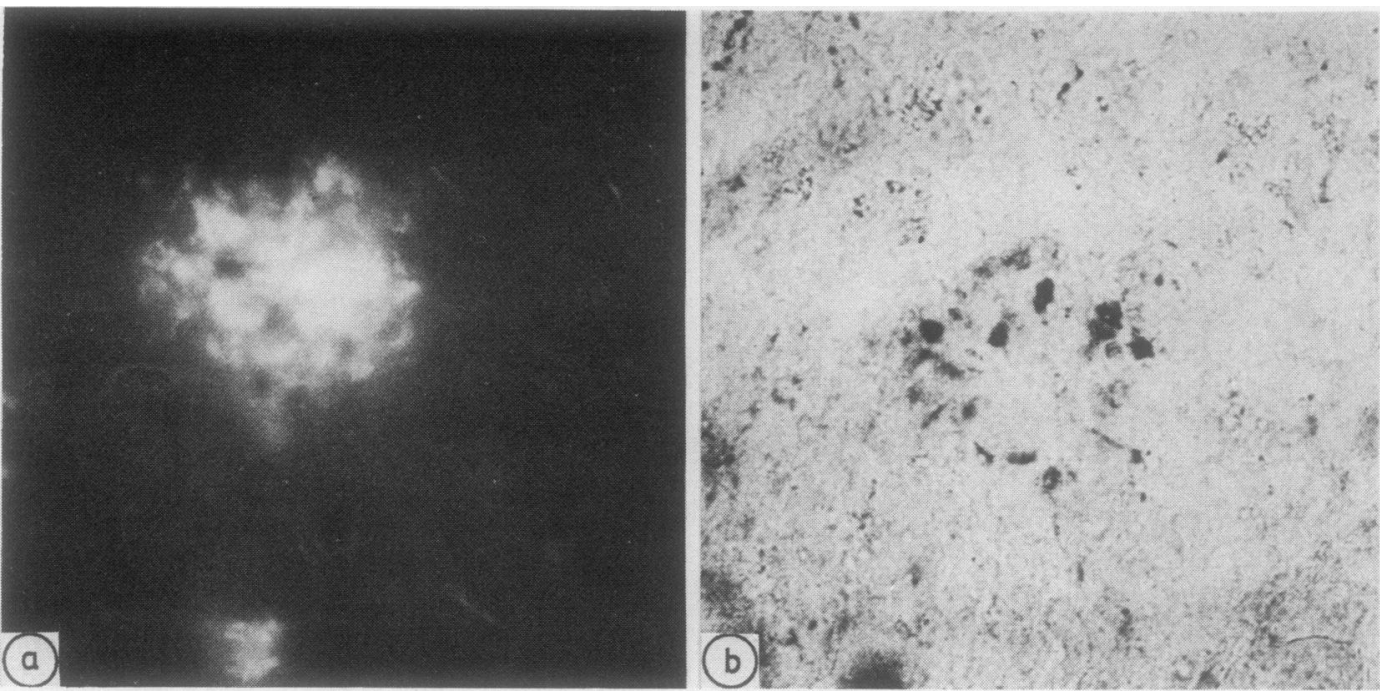

Fig 4 Argyrophilic plaque double stained by treatment with monoclonal antibody SMP detected with fluorescein (a) and monoclonal antibody $R T 97$ detected with peroxidase $(b)$. Reaction is more extensive with SMP than with RT97. $\times 800$.

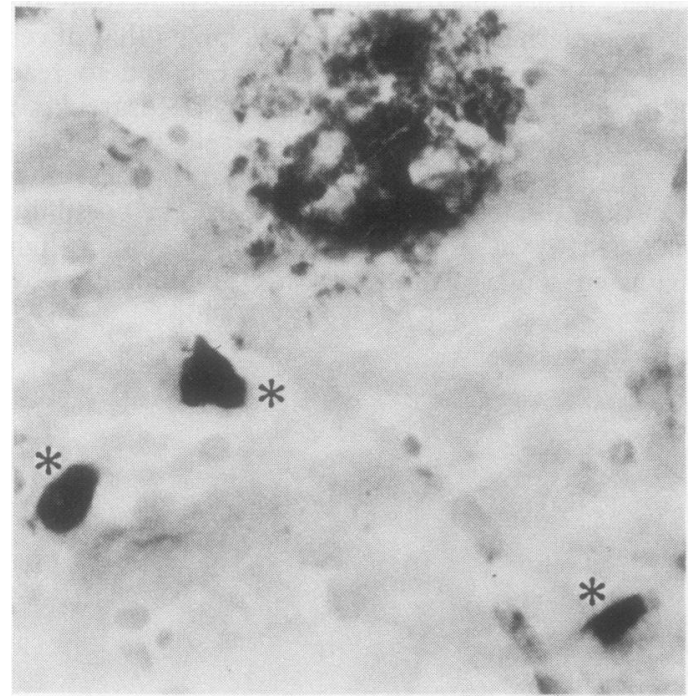

Fig 5 Cryosat section of Alzheimer cortex treated with SMP monoclonal antibody with sites of binding detected by the peroxidase reaction with diaminobenzidine.

Neurofibrillary tangles (*) bind monoclonal antibody. $\times 500$.

obtained no noticeable staining with antisera (Dako) to light chains.

Investigation of frozen sections of human cerebral cortex from cases of cerebral infarction and head injury showed no noticeable staining using SMP monoclonal antibody, apart from the slight staining of vascular elements seen in normal brain.

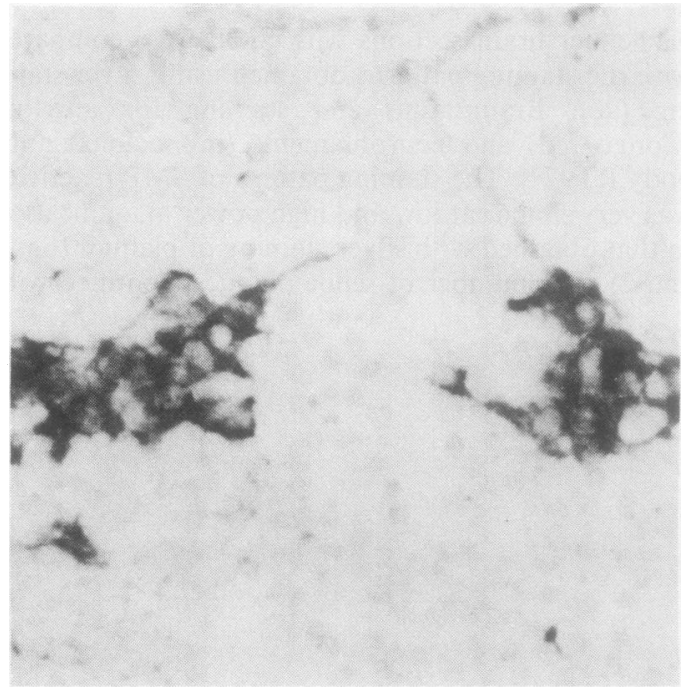

Fig 6 Smear from tonsil treated with SMP monoclonal antibody with site of binding detected by peroxidase reaction with diaminobenzidine. Cells with appearances of dendritic reticulum cells react with monoclonal antibody. $\times 550$.

\section{Discussion}

These observations show that SMP binds to an epitope in Alzheimer brain, which has a distribution resembling that of the silver stained elements of argyrophilic plaques, congophilic elements in leptomeningeal and cortical blood vessels, and 
neurofibrillary tangles. The SMP antigen, therefore, seems to be common to all these pathological features. The staining pattern obtained in Alzheimer brain differs from that obtained with the neurofilament antibody RT97 in that plaque staining was more extensive with SMP than with RT97 and the vascular amyloid was stained by SMP but not by RT97. By electron microscopy plaques seem to be composed of degenerate neuritic processes that contain mitochondria, dense bodies, and paired helical filaments resembling those of neurofibrillary tangles. ${ }^{1}$ Astrocytic and microglial processes may also participate in plaque structure, and extracellular amyloid deposits can be identified in plaques. Astrocytes and microglial cells in and around resolving cerebral infarcts did not react with SMP. In normal brain SMP bound minimally and only to vascular elements. The observation of binding of SMP to a small proportion of peripheral blood mononuclear cells using the FACS could not be confirmed in blood smears. The SMP antigen, however, was clearly present in germinal centres of lymphoid follicles where it seemed to react with dendritic reticulum cells. Many antigenic determinants common to lymphoid and central nervous system tissues have been detected using other monoclonal antibodies, ${ }^{6}$ but to our knowledge none of these has been related to follicular dendritic cells, nor to Alzheimer brain. The biochemical nature of the SMP antigen has proved difficult to determine, and so far attempts to immunoprecipitate or immunoblot the antigen present in tonsil tissue and Alzheimer cerebral cortex have failed to establish the molecular weight of the antigen.

The findings presented here of an antigen common to cerebral amyloid, argyrophilic plaques, and neurofibrillary tangles in Alzheimer's disease support the suggestion by Kidd et $\mathrm{al}^{7}$ that these features share a common protein. Further investigations using this monoclonal antibody may prove of value in attempting to understand the nature of the neuronal degeneration that causes Alzheimer's disease.

MME received financial support from the Medical Research Council. We are grateful to Mr R Cross, who performed some silver staining of sections; Drs S Leibowitz and DY Mason, who provided valuable advice and discussion; and $\mathrm{Dr} \mathrm{BH}$ Anderton, who provided supplies of RT97 monoclonal antibody.

\section{References}

1 Tomlinson BE, Corsellis JAN. Ageing and the dementias. In: Hume Adams J, Corsellis JAN, Duchen LW, eds. Greenfield's neuropathology. 4th ed. London: Arnold, 1984:951-1025.

2 Ishii $T$, Haga S. Identification of components of immunogobulins in senile plaques by means of fluorescent antibody technique. Acta Neuropathol 1975;32:157-62.

3 Anderton BH, Breinberg D, Downes MJ, et al. Monoclonal antibodies show that neurofibrillary tangles and neurofilaments share antigenic determinants. Nature 1982;298:84-6.

4 Isersky C, Ein D, Horada M, Glenner GG. Immunochemical cross-reactions of human amyloid protein with human immunoglobulin light polypeptide chains. J Immunol 1972;108:486.

5 Kalyan-Raman UP, Kalyan-Raman K. Cerebral amyloid angiopathy causing intracranial haemorrhage. Ann Neurol 1984; 16:321-9.

6 Budka H, Majdic O. Shared antigenic determinants between human hemopoietic cells and nervous tissues and tumours. Acta Neuropathol 1985;67:58-66.

7 Kidd M, Allsop D, Landon M. Senile plaque amyloid, paired helical filaments and cerebrovascular amyloid in Alzheimer's disease are all deposits of the same protein. Lancet 1985;i:278.

Requests for reprints to: Dr MM Esiri, Department of Neuropathology, The Radcliffe Infirmary, Oxford OX2 6HE, England. 